\title{
Microbiología de la caries radicular en el paciente mayor
}

\author{
Gutiérrez Acero D*, Alós Cortés L**, García Gómez F***, González Sanz A****
}

\section{RESUMEN}

La caries radicular es uno de los problemas bucodentales más importantes y que más comúnmente afectan al adulto mayor. La caries radicular es aquel proceso carioso que se produce sobre la raíz expuesta del diente. Los principales patógenos implicados son el Streptococcus mutans, el Actinomyces viscosus y el Lactobacillus acidofilus, que producen los ácidos orgánicos que desmineralizan el cemento y la dentina de la raíz, llegando producir su cavitación. Los cambios que se producen en el medio oral tienen una relación muy directa con las bacterias de la caries radicular y del biofilm que forman.

Palabras clave: Caries, radicular, paciente mayor, Streptococcus mutans, Lactobacillus, biofilm.

\section{SUMMARY}

The root caries is one of most important bucodental problems that affect to the old patient. The root caries is the decay process that produce on the expose root. The principals pathogens relying are Streptococos mutans, Actinomyces viscosus and Lactobacillus acidofilus, that produce the organics acids demineralizating of root cement and dentin producing the cavitation of the root. The changes producing in the mouth have a direct relation with the bacteria and its biofilm.

Key words: Caries, root, old patient, Streptococcus mutans, Lactobacillus, biofilm.

Aceptado para publicación: Mayo 2005.

* $\quad$ Profesor Honorífico de la Universidad Rey Juan Carlos (URJC)

** Profesor Asociado de la Universidad Rey Juan Carlos (URJC)

*** Profesor Titular Interino de la Universidad Rey Juan Carlos (URJC)

**** Profesor Titular Comisión de Servicios de la Universidad Rey Juan Carlos

Gutiérrez Acero D, Alós Cortés L, García Gómez F, González Sanz A. Microbiología de la caries radicular en el paciente mayor. Av. Odontoestomatol 2006; 22-2: 125-130.

\section{INTRODUCCIÓN}

La población mayor está experimentado un incremento en los últimos años. Gracias a la instauración de nuevos tratamientos y de la mejora en las condiciones de vida; las personas mayores pueden disfru- tar de una vejez acorde con los nuevos conceptos sociales del siglo XXI.

A nivel bucodental este cambio se ha traducido en una mejora de las cualidades dentales de nuestros mayores, es decir, cada vez más se ven en las clíni- 
cas personas mayores con un elevado número de dientes presentes en boca. De igual manera, las enfermedades que pueden presentar éstos dientes son el objetivo de tratamiento demandado por éstos pacientes en nuestras clínicas. Dentro de éstas enfermedades, la caries radicular es la presentación clínica de la caries más frecuente en los estudios realizados sobre el estado de la salud bucodental de las personas mayores en nuestro país y en otros países del mismo nivel socio-económico (1-5).

La caries radicular es aquel proceso carioso que se produce sobre la raíz del diente. Hay autores que indican una posible relación entre la presencia de caries radicular y la concentración de albúmina sérica en sangre. Señalando de ésta manera el posible impacto que una enfermedad oral puede tener sobre la salud general (6). Como generalmente el paciente mayor suele tener una salud comprometida por diferentes patologías, la caries radicular vendría a desestabilizar el delicado equilibrio que tienen muchos de éstos pacientes. Conocer los distintos factores que influyen en el inicio y posterior desarrollo de la caries radicular parece ser de extrema importancia a la hora de proporcionar un tratamiento adecuado y de calidad en función de las necesidades asistenciales que demanden éste tipo de pacientes.

Es bien conocido que la caries es una enfermedad infecciosa de origen bacteriano que se produce por la desmineralización de los tejidos duros del diente, que en el caso de la caries radicular éstos serían el cemento y la dentina $(7,8)$. Tenemos siempre que tener en cuenta que para que se produzca una caries radicular la raíz dentaria tiene que haberse expuesto al medio ambiente oral previamente $(9,10)$.

\section{CARACTERÍSTICAS MICROBIOLOGICAS DE LA CARIES RADICULAR}

Como ya se conoce, la presencia de las bacterias desencadenantes del proceso carioso es fundamental para la instauración de una caries. Tradicionalmente se ha identificado al Streptococcus mutans, al Actinomyces viscosus y al Lactobacillus acidophilus con el inicio y la progresión de la caries radicular. Más concretamente, al S. mutans como el iniciador de la caries radicular y al Lactobacillus en caries de raíz en estadio avanzado (11). Pero no se ha podido encontrar una relación significativa y clara entre ciertos niveles de la presencia de éstos dos patógenos orales con el diagnóstico de la caries radicular $(12,13)$.

Se sabe que estas bacterias crecen y se desarrollan en la llamada placa bacteriana. Tradicionalmente se ha definido a la placa bacteriana como una colección de colonias bacterianas formando parte de un material amorfo que se encuentra firmemente adherido a las superficies dentarias y de la mucosa oral (14).

Actualmente y gracias a las nuevas técnicas de observación en microscopia, se ha podido valorar como se organizan las bacterias surgiendo un nuevo concepto, el concepto de biofilm. Concepto que viene a explicar las relaciones internas que se producen entre las bacterias que forman parte de la placa bacteriana. Hoy se sabe que para que se establezca y progrese una caries radicular se necesitan de una serie de asociaciones y componentes bacterianos que formen el biofilm que conforme a la placa bacteriana dental. Antiguamente se han analizado las cualidades de las distintas bacterias aisladas, con el concepto de biofilm las bacterias al relacionarse unas con otras éstas cualidades pueden cambiar siendo más prevalentes aquellas que más útiles pueden resultar para el biofilm. Según Marsh (1999) (15), las principales tres características de las bacterias cariogénicas podrían quedar resumidas en:

- La primera sería la rápida capacidad para transportar al interior de la bacteria los azúcares fermentables necesarios para su metabolismo y para la producción de los ácidos bacterianos, compitiendo así con otras bacterias integrantes del biofilm bacteriano. Se sabe del receptor fosfoenolpiruvato fosfotransferasa presente en el S. mutans, que lo capacitaría para captar glucosa en concentraciones muy bajas en el medio oral, lo que lo pondría en una situación de ventaja frente a otras bacterias.

- La segunda característica que tendrían las bacterias cariogénicas sería la capacidad de producción de polisacáridos extracelulares (glucanos y fructanos) e intracelulares. Los compuestos intracelulares actuarían de reservorio de energía 
para aquellos casos en que hay una restricción de nutrientes en el medio. Los glucanos contribuirían a la formación de la matriz del biofilm de placa bacteriana. Y los fructanos servirían también como reservorio de azúcares, al igual que los intracelulares, pero para poder ser utilizados por cualquier bacteria del biofilm.

- La tercera característica de éstas bacterias sería la capacidad para mantener el metabolismo bacteriano en condiciones muy extremas. Es decir, la capacidad de las bacterias de ser acidogénicas y acidúricas.

Por tanto la mayoría de los microorganismos relacionados con la placa bacteriana cariogénica producen ácido en presencia de carbohidratos, es decir, son acidogénicos; y se desarrollan mejor en condiciones de $\mathrm{pH}$ bajo del medio oral; son, por tanto, acidúricos. La cariogenicidad del biofilm podría aumentar con la mayor retención de los nutrientes bacterianos (16) o por la mayor permanencia de los ácidos orgánicos que estarían mayor tiempo en contacto con la superficie del diente por el impedimento físico que supondría el biofilm a la aclaración de los mismos (17). Esto provocaría el conocido proceso de desmineralización de la matriz inorgánica del cemento y de la dentina. Así pues, hay estudios que hablan que las dos especies predominantes en el biofilm bacteriano cariogénico serían el $S$. mutans y el Lactobacillus spp. $(18,19)$. Los últimos estudios hablan también de la presencia de otras especies de Streptococcus de características acidúricas, como el $S$. sobrinus (20). Dentro de los Streptococcus spp., el genotipo que más frecuentemente aparece aislado es el de $S$. mutans aunque no aparecen diferencias de aislamiento entre el tejido careado y el no careado (21).

También se han identificado otras especies de Actinomyces, como el $A$. naeslundii $(19,22)$, que estarían relacionadas con la caries radicular (23). Parece ser que el Actinnomyces spp. tendrían un doble papel en la instauración y actividad del biofilm cariogénico. Por un lado, los últimos estudios revelan que Actinnomyces spp. desarrollarían un papel fundamental en la instauración del biofilm siendo una de las especies, junto con Estreptococos spp., que con más prontitud colonizaría la superficie del diente y que serviría para que otras especies cariogénicas (como Lactobacillus spp. (24)) y periodontopatógenas se estableciesen formando el biofilm (25, 26). Por otro lado, se conoce de sus cualidades cariogénicas (22, 23); Bowden et al. (1999) hicieron un estudio en el que encontraron diversos genotipos de A. naeslundii en individuos con caries radicular activa dentro del biofilm bacteriano, concluyeron que no es tan importante el genotipo de las bacterias como el fenotipo. La destrucción del tejido mineral del diente depende más del comportamiento fisiológico de las bacterias dentro del biofilm que de la información genética que llevan (27). Parece ser, que conforme el ataque bacteriano progresa se produciría un cambio en las proporciones de S. mutans, a favor de Lactobacillus spp. dentro del biofilm (18) por un cambio en las condiciones ambientales hacia un medio más ácido.

También es de gran importancia señalar la relación que tiene la saliva en la instauración del biofilm bacteriano, así la capacidad de agregación y adherencia de las bacterias del biofilm se vería influida, en gran parte, por proteínas presentes en la saliva. Se conocen receptores de proteínas salivares presentes en Actinomyces spp. y Estreptococos spp. que influirían en la adhesión de éstas bacterias, primeros colonizadores de la superficie dental (28). La mejor o peor capacidad de adherencia de las bacterias a esas proteínas salivales sería fundamental para poder definir el posible potencial cariogénico de cada bacteria $(29,30)$. Aunque también se sabe que dentro de los componentes de la saliva se encuentran IgA, lactoferrina, y lisozima, entre otros; cuya función sería la de proteger a las estructuras dentales de la invasión bacteriana. Hay estudios que reflejan cambios en la concentración de estos componentes salivales pero sin una relevancia significativa aplicable al diagnóstico de caries radicular $(30,31)$. Parece haber un acuerdo unánime que relaciona la presencia de hiposalivación con el mayor riesgo a padecer caries radicular (3236). Incluso hay autores que relacionan un bajo volumen de saliva no estimulada y bajas concentraciones en ella de fosfatos y amilasas, como posibles factores predisponentes a padecer caries radicular (37).

Por otra parte, se ha discutido desde hace tiempo el papel que podría jugar la Cándida albicans en progresión de la caries radicular. Ya que se sabe que 
pertenece a la flora comensal de la boca y es frecuente que colonice las prótesis removibles (38-41). Parece ser que su función sería la de acidificar el medio oral favoreciendo la desmineralización de la matriz inorgánica de la dentina. Incluso, se ha planteado la posibilidad que la Cándida albicans colonice la dentina careada en los pacientes HIV positivo, siendo un reservorio muy importante a tener en cuenta para disminuir la incidencia de candidiasis en éste tipo de pacientes (42).

La presencia de Streptococcus mutans en la placa subgingival, incluso después de la terapia periodontal, podría explicar cómo la zona subgingival formaría un nicho ecológico que podría tener mucha importancia en el desarrollo de la caries radicular en el paciente periodontal. Y así podría ser valorable la inclusión de la prevención de la caries de raíz dentro del protocolo de tratamiento y mantenimiento del paciente con periodontitis (43-46). Y al revés, ya que sin la exposición de la raíz producida por la enfermedad periodontal no habría la posibilidad del ataque patógeno de las bacterias cariogénicas.

Hay autores que resaltan el aumento en el recuento de S. mutans y de Lactobacillus en los portadores de prótesis removibles. Parece ser que la prótesis parcial removible actuaría de reservorio (47), creando las condiciones medioambientales favorables a estas bacterias y disminuiría la función de clearance de la saliva (48). En definitiva, los portadores de prótesis parcial removible tienen mayor posibilidad de padecer caries radicular (49).

Otros patógenos orales presentes en el biofilm bacteriano supra y subgingival, y que se desconoce si desarrollan algún papel en el inicio o en la progresión de la caries radicular como participantes en la formación de la estructura del biofilm; son, generalmente patógenos periodontales, Fusobacterium nucleatum, Prevotella spp., Campylobacter rectus, Capnocytophaga spp., Peptosteptococos y Eikenella corrodens $(13,19)$ entre otros.

\section{CONCLUSIONES}

En la instauración y desarrollo de la caries radicular son muy importantes las relaciones entre las bacte- rias que se producen cuando se establece el biofilm bacteriano. Dependiendo de las distintas condiciones que se producen en el medio oral varía la capacidad virulenta del biofilm. Conocer las características y condiciones orales son muy importantes de analizar para poder aplicar los tratamientos preventivos más efectivos, como dice Fejerskov (2004) (50).

Se necesitan más investigaciones que expliquen las características del biofilm bacteriano oral y su relación con la caries radicular. Al igual es necesario investigar y valorar la posible relación de los patógenos periodontales con el establecimiento del biofilm cariogénico.

\section{BIBLIOGRAFÍA}

1. The Spanish Geriatric Oral Health Research Group Oral health issues of spanish adults aged 65 and over. The Spanish Geriatric Oral Health Research Group. Int Dent J 2001;51(3 Suppl): 228-34.

2. Henriksen BM, et al. Dental caries among the elderly in Norway. Acta Odontol Scand. 2004;62 (2):75-81.

3. Fure S. Ten-year incidence of tooth loss and dental caries in elderly Swedish individuals. Caries Res. 2003;37(6):462-9.

4. Splieth $\mathrm{Ch}$, et al. Prevalence and distribution of root caries in Pomerania, North-East Germany. Caries Res. 2004;38(4):333-40.

5. Chalmers JM, et al. Caries experience in existing and new nursing home residents in Adelaide, Australia. Gerodontology. 2002;19(1):30-40.

6. Yoshihara A, et al. Association between serum albumin and root caries in community-dwelling older adults. J Dent Res. 2003;82(3):218-22.

7. Bullón Fernández, P; Velasco Ortega, E. Odontoestomatología Geriátrica: La Atención Odontológica Integral del Paciente de Edad Avanzada. Madrid, 1996.

8. Holm-Pedersen, P; Loe, H. Textbook of Geriatric Dentistry. Muksgaard, 2 Ed., Copenhagen 1996.

9. Van Strijp AJ, et al. Bacterial colonization of mineralized and completely demineralized dentine in situ. Caries Res. 1997;31(5):349-55.

10. Tugnait A, Clerehugh V. Gingival recession-its significance and management. J Dent. 2001;29 (6):381-94. 
11. Zambon JJ, Kasprzak SA. The microbiology and histopathology of human root caries. Am J Dent. 1995;8(6):323-8.

12. van Strijp AJ, et al. Bacterial colonization of mineralized and completely demineralized dentine in situ. Caries Res. 1997;31(5):349-55.

13. Aamdal-Scheie A, et al. Plaque pH and microflora of dental plaque on sound and carious root surfaces. J Dent Res. 1996; 75 (11):1901-8.

14. Rioboo R. Odontología Preventiva y Odontología Comunitaria. Ed. Avances Madrid. 2002.

15. Marsh PD. Microbiologic aspects of dental plaque and dental caries. Dent Clin North Am. 1999; 43 (4):599-614, v-vi.

16. Zaura E, ten Cate JM. Dental plaque as a biofilm: a pilot study of the effects of nutrients on plaque $\mathrm{pH}$ and dentin demineralization. Caries Res. 2004;38 Suppl 1:9-15.

17. Shen $\mathrm{S}$, et al. In vitro growth, acidogenicity and cariogenicity of predominant human root caries flora. J Dent. 2004;32(8):667-78.

18. Shu $M$, et al. Development of multi-species consortia biofilms of oral bacteria as an enamel and root caries model system. Arch Oral Biol. 2000;45(1):27-40.

19. Shen $S$, et al. Bacterial and yeast flora of root surface caries in elderly, ethnic Chinese. Oral Dis. 2002; 8 (4):207-17.

20. Lundgren $M$, et al. Root caries and some related factors in 88-year-old carriers and non-carriers of Streptococcus sobrinus in saliva. Caries Res. 1998;32(2):93-9.

21. Nascimento $M M$, et al. Streptococcus mutans genotypes isolated from root and coronal caries.Caries Res. 2004;38(5):454-63.

22. Brailsford SR, et al. The predominant Actinomyces spp. isolated from infected dentin of active root caries lesions. J Dent Res. 1999; 78 (9):1525-34.

23. Brailsford SR, et al. The predominant aciduric microflora of root-caries lesions. J Dent Res. 2001; 80 (9):1828-33.

24. Filoche SK, et al. Biofilm growth of Lactobacillus species is promoted by Actinomyces species and Streptococcus mutans. Oral Microbiol Immunol. 2004; 19(5):322-6.

25. Ramberg P, et al. Bacterial colonization during de novo plaque formation. J Clin Periodontol. 2003; 30(11):990-5.
26. Shen S, et al. Coaggregation profiles of the microflora from root surface caries lesions. Arch Oral Biol. 2005;50(1):23-32.

27. Bowden $\mathrm{GH}$, et al. The diversity and distribution of the predominant ribotypes of Actinomyces naeslundii genospecies 1 and 2 in samples from enamel and from healthy and carious root surfaces of teeth. J Dent Res. 1999;78(12):1800-9.

28. Ruhl S, et al. Salivary receptors for the prolinerich protein-binding and lectin-like adhesins of oral actinomyces and streptococci. J Dent Res. 2004;83(6):505-10.

29. Stenudd C, et al. The association of bacterial adhesion with dental caries. J Dent Res. 2001; 80(11):2005-10.

30. Rudney JD, et al. Streptococcal diversity in oral biofilms with respect to salivary function. Arch Oral Biol. 2003;48(7):475-93.

31. Kirstila V, et al. Longitudinal analysis of the association of human salivary antimicrobial agents with caries increment and cariogenic micro-organisms: a two-year cohort study. J Dent Res. 1998;77(1):73-80.

32. Thomson WM, et al. Is medication a risk factor for dental caries among older people? Community Dent Oral Epidemiol 2002;30(3): 224-32.

33. Cassolato SF, Turnbull RS. Xerostomia: clinical aspects and treatment. Gerodontology. 2003;20 (2):64-77.

34. Almstahl A, Wikstrom M. Oral microflora in subjects with reduced salivary secretion. J Dent Res. 1999;78 (8):1410-6.

35. Janket SJ, et al. Xerostomic medications and oral health: the Veterans Dental Study (part I); Gerodontology. 2003;20(1):41-9.

36. Bardow A, et al. Relationships between medication intake, complaints of dry mouth, salivary flow rate and composition, and the rate of tooth demineralization in situ. Arch Oral Biol. 2001;46(5):413-23.

37. Bardow A, et al. Effect of saliva composition on experimental root caries. Caries Res. 2005;39(1): 71-7.

38. Kuc IM, et al. Oral health and microflora in an institutionalised elderly population in Canada. Int Dent J. 1999; 49(1):33-40.

39. Grimoud AM, et al. Colonization of the oral cavity by Candida species: risk factors in long-term geriatric care. J Oral Sci. 2003;45(1):51-5. 
40. Sumi Y, et al. High correlation between the bacterial species in denture plaque and pharyngeal microflora. Gerodontology. 2003;20 (2): 84-7.

41. Ramage G, et al. Denture stomatitis: a role for Candida biofilms. Oral Surg Oral Med Oral Pathol Oral Radiol Endod. 2004;98(1):53-9.

42. Jacob LS, et al. Role of dentinal carious lesions in the pathogenesis of oral candidiasis in HIV infection. J Am Dent Assoc. 1998;129(2):187-94.

43. Quirynen $M$, et al. The effect of periodontal therapy on the number of cariogenic bacteria in different intra-oral niches. J Clin Periodontol. 1999;26(5):322-7.

44. Van der Reijden WA, et al. Mutans streptococci in subgingival plaque of treated and untreated patients with periodontitis. J Clin Periodontol. 2001;28(7):686-91.

45. Reiker J, et al. A cross-sectional study into the prevalence of root caries in periodontal maintenance patients. J Clin Periodontol. 1999;26(1): 26-32.

46. Renvert S, Persson GR. Supportive periodontal therapy. Periodontol 2000. 2004; 36:179-95.
47. Narhi TO, Kurki N, Ainamo A. Saliva, salivary micro-organisms, and oral health in the homedwelling old elderly-a five-year longitudinal study. J Dent Res. 1999;78(10):1640-6.

48. Fure S. Five-year incidence of caries, salivary and microbial conditions in 60-, 70- and 80-year-old Swedish individuals. Caries Res. 1998;32(3):16674.

49. Davenport JC, et al. Removable partial dentures. 1. Need and demand for treatment. Br Dent J. 2000;14;189(7):364-8.

50. Fejerskov O. Changing paradigms in concepts on dental caries: consequences for oral health care. Caries Res. 2004;38(3):182-91.

\section{CORRESPONDENCIA}

Daniel Gutiérrez Acero

San Valeriano, $11,2^{\circ}-3$

28039 Madrid

e-mail: daguaz@yahoo.es 